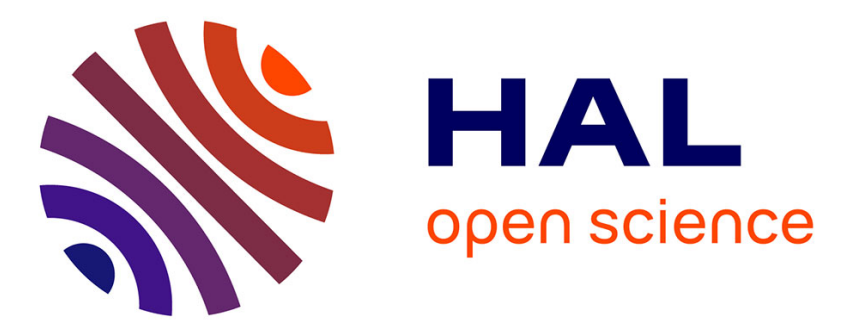

\title{
Featuring non-covalent interactions in m-xylylenediaminium bis(perchlorate) monohydrate Synthesis, characterization and Hirshfeld surface analysis
}

Afef Guesmi, Thierry Roisnel, Houda Marouani

\section{To cite this version:}

Afef Guesmi, Thierry Roisnel, Houda Marouani. Featuring non-covalent interactions in mxylylenediaminium bis(perchlorate) monohydrate Synthesis, characterization and Hirshfeld surface analysis. Journal of Molecular Structure, 2019, 1194, pp.66-72. 10.1016/j.molstruc.2019.04.124 . hal-02177792

HAL Id: hal-02177792

https://hal-univ-rennes1.archives-ouvertes.fr/hal-02177792

Submitted on 17 Sep 2019

HAL is a multi-disciplinary open access archive for the deposit and dissemination of scientific research documents, whether they are published or not. The documents may come from teaching and research institutions in France or abroad, or from public or private research centers.
L'archive ouverte pluridisciplinaire HAL, est destinée au dépôt et à la diffusion de documents scientifiques de niveau recherche, publiés ou non, émanant des établissements d'enseignement et de recherche français ou étrangers, des laboratoires publics ou privés. 


\title{
Featuring non-covalent interactions in $\mathbf{m}$-xylylenediaminium bis(perchlorate) monohydrate: synthesis, characterization and Hirshfeld surface analysis
}

\author{
Afef Guesmi (a), Thierry Roisnel (b) and Houda Marouani ${ }^{(a)^{*}}$
}

(a) Université de Carthage, Faculté des Sciences de Bizerte, LR13ES08 Laboratoire de Chimie des

$$
\text { Matériaux, 7021, Bizerte,Tunisie }
$$

(b) Université de Rennes, CNRS, ISCR (Institut des Sciences Chimiques de Rennes) - UMR 6226, F35000 Rennes, France

\footnotetext{
*Corresponding author: houdamarouani2015@gmail.com
}

\begin{abstract}
The novel compound $\left(\mathrm{C}_{8} \mathrm{H}_{14} \mathrm{~N}_{2}\right)\left(\mathrm{ClO}_{4}\right)_{2} \cdot \mathrm{H}_{2} \mathrm{O}\left(\mathrm{MXClO}_{4}\right)$ has been elaborated by slow evaporation at room temperature and characterized by X-ray single crystal analysis, Hirshfeld surface analysis, differential scanning calorimetry analysis (DSC), IR and Raman spectroscopies. $\mathrm{MXClO}_{4}$ crystallized in the monoclinic system, space group $\mathrm{P} 2{ }_{1} / \mathrm{c}$, with $\mathrm{a}=$ 5.5781(10) $\AA, b=11.1137(3) \AA, c=23.0731(7) \AA, \beta=95.414(1)^{\circ}, V=1424.0(3) \AA^{3}$ and $Z=$ 4. The asymmetric unit of the title compound contains one m-xylylenediaminium cation, two perchlorate anions and one water molecule. The atomic arrangement of the title compound can be described by a three-dimensional network. Therefore, chlorine atoms, $\mathrm{Cl} 2$, are discrete and $\mathrm{Cl1}$ form with water molecules corrugated $C$ (5) 勇finite chains of formula $\left(\mathrm{ClH}_{2} \mathrm{O}_{5}\right)_{n}^{n}{ }_{n}$ extending along the $\boldsymbol{a}$-axis at $\mathrm{z}=1 / 4$ and $3 / 4$. These inorganic entities are allied to organic cations $\left(\mathrm{C}_{8} \mathrm{H}_{14} \mathrm{~N}_{2}\right)^{2+}$ through involved hydrogen bonding. The intermolecular interactions were further evaluated by using the three-dimensional Hirshfeld surfaces and two-dimensional fingerprint plots. The hydrogen bonding interactions associated to OW-H... , N-H..., $\mathrm{N}-$ H...OW and $\mathrm{C}-\mathrm{H} . . \mathrm{O}$ represent the top fraction of $69.1 \%$ followed by these of the H...H type contributing $17.5 \%$.
\end{abstract}

Keywords: Crystal structure; hydrogen bonding; Hirshfeld surface analysis; IR spectroscopy; Photoluminescence. 


\section{Introduction}

The hybrid materials are interesting because of their properties to combine the characteristics of both organic and inorganic components. Potential applications have been described for such diverse fields as catalysis, optics, electronics, medicine, conductivity and biology. For this purpose, m-xylylenediamine was chosen as organic part due to its good antimicrobial activity against various antibacterial and antifungal species [32].

In particular, perchlorate salts containing organic cations have been extensively reviewed [1'], so they represent high performance materials due to their interesting physicochemical properties and a high solubility and poor adsorption [1"]. The tetrahedron structure and high activity of perchlorate cause that the oxidizing power is deferred. Perchlorate is mainly used in explosives and fireworks, rocket propellants, for manufacturing matches, ammunitions, fertilizers and air bag inflators [1,2]. Since, its first recognition in water source in 1997 [3] and it has been successively discovered in drinking water [4], food, milk [5], snow, soil, corns [6, 7], fruits, vegetables, beverages, seafood and edible plant species $[8]$.

The perchlorate ion is toxic. It was confirmed that it can affect health even at low because its ability to interfere with iodine uptake by the thyroid gland resulting in decreased production of the thyroid gland as an endocrine disruptor [9-11].

The perchlorate anions in the organic-inorganic hybrid compounds can be discrete or they can form clusters [12] or infinite chains [13, 14] with the water molecules in hydrated compounds. In addition, in these hybrid materials the perchlorate anions and organic cations are interrelated by electrostatic and van der Waals interactions which, together with hydrogen bonds, build a two or three-dimensional networks.

As a part of our study of crystal packing inclosing the perchlorate anion [13, 14], we report in the present paper the chemical preparation of a new organic-inorganic compound $\left(\mathrm{C}_{8} \mathrm{H}_{14} \mathrm{~N}_{2}\right)\left(\mathrm{ClO}_{4}\right)_{2} \cdot \mathrm{H}_{2} \mathrm{O}$ and the characterization by single crystal structural study and Hirshfeld surfaces investigation to clarify the nature of the intermolecular interactions. Thus, by changing the piperazine-based organic molecule with another one based on xylylenediamine, we notice the formation of cycle stacking that add to the non-covalent interactions of hydrogen bonds and C-H...O interactions. Besides, as no other physical and chemical properties of our previous perchlorate crystals have been reported except the crystal structure, FTIR and FT-Raman spectroscopic studies, elemental analysis, UV-vis, 
photoluminescence, calorimetry and Hirshfeld surface surveys of $\mathrm{MXClO}_{4}$ have been carried out and discussed in this paper.

\section{Experimental methods}

\subsection{Synthesis of $\left(\mathrm{C}_{8} \mathrm{H}_{14} \mathrm{~N}_{2}\right)\left(\mathrm{ClO}_{4}\right)_{2} \cdot \mathrm{H}_{2} \mathrm{O}$}

The target compound, $\left(\mathrm{C}_{8} \mathrm{H}_{14} \mathrm{~N}_{2}\right)\left(\mathrm{ClO}_{4}\right)_{2} \cdot \mathrm{H}_{2} \mathrm{O}$ (I) was prepared from a solution containing $1 \mathrm{mmol}$ of m-xylylenediamine $(0.1 \mathrm{~g}$, purity $99 \%$, Aldrich) dissolved in methanol $(10 \mathrm{~mL})$ and $2 \mathrm{mmol}$ of an aqueous perchloric acid $\mathrm{HClO}_{4}(0.2 \mathrm{~g}$, purity $96 \%$, Aldrich) stirred for about $1 \mathrm{~h}$. These the solid products were filtered off, dried and repeatedly recrystallized as colorless prisms to enhance the purity of the product. The reaction scheme is written as follows:

$$
\mathrm{C}_{8} \mathrm{H}_{12} \mathrm{~N}_{2}+2 \mathrm{HClO}_{4}+\mathrm{H}_{2} \mathrm{O} \stackrel{\mathrm{T}=25^{\circ} \mathrm{C}}{\longrightarrow}\left(\mathrm{C}_{8} \mathrm{H}_{14} \mathrm{~N}_{2}\right)\left(\mathrm{ClO}_{4}\right)_{2} \cdot \mathrm{H}_{2} \mathrm{O}
$$

Elemental analysis, calc. (found): C, 27.02\%(27.11); H, 4.50\%(4.53); N, $7.88 \%(7.91)$.

\subsection{Physical measurements}

Intensities of X-ray diffracted were assembled at $150 \mathrm{~K}$ by means of a diffractometer BrukerAXS APEXII, functioning at molibdene wavelength. Absorption corrections were performed by the multi-scan technique using the SADABS program [15]. Amongst the 17246 reflections collected only 3252 are independent, the remnants remaining 3006 reflections had an intensity $\mathrm{I}>2 \sigma(\mathrm{I})$. The structure was solved by direct methods using theSIR97 program [16] and then refined with full-matrix least-square methods based on $F^{2}$ (SHELXL-97) [17] with the help of the WINGX program [18]. All non-hydrogen atoms were refined with anisotropic atomic displacement parameters. All the hydrogen atoms bonded to carbon atoms were placed in calculated positions and refined with fixed individual displacement parameters $\left[\mathrm{U}_{\mathrm{iso}}(\mathrm{H})=\right.$ $\left.1.2 U_{\mathrm{eq}}\right]$ according to the riding model (C-H (aromatic, methylene) bond lengths of $0.93 \AA$ and $0.97 \AA$, respectively). The hydrogen atoms bonded to water oxygen atoms were located from a difference map and were allowed to refine using restraints $[\mathrm{O}-\mathrm{H}=0.85$ (1) $\AA, \mathrm{H}$...H $=$ $1.44(2) \AA$ and $\left.U_{\text {iso }}(\mathrm{H})=1.5 U_{\text {eq }}(\mathrm{O})\right]$. The remaining hydrogen atoms, which are connected to nitrogen atoms, were located in a difference map.

A final refinement on $F^{2}$ converged at $R\left(F^{2}\right)=0.031$ and $\mathrm{w} R\left(F^{2}\right)=0.081$. The parameters used for the X-ray data collection as well as the strategy for the crystal structure determination and its final results are reported in Table 1. An ORTEP [18] drawing of the molecular structure is shown in Fig. 1. 
Elemental analyses were realized on a Perkin-Elmer 2400 CHN Elemental Analyzer.

Infrared spectrum was registered at a room temperature on a Nicolet IR 200 FTIR spectrophotometer in the $4000-400 \mathrm{~cm}^{-1}$ region using an ATR technique with a spectral resolution of $4 \mathrm{~cm}^{-1}$.

Fluorescent spectra were recorded for the solid sample at room temperature with PerkinElmer LS55 spectrofluorometer. The slit widths used for the excitation and emission measurements were 2.5 and $11.5 \mathrm{~nm}$ respectively. Differential scanning calorimetry analysis was realized using a multimodule 92 Setaram analyzer operating from room temperature up to $600 \mathrm{~K}$ at an average heating rate of $5 \mathrm{~K} / \mathrm{min}$ and the mass of the simple was $8.7 \mathrm{mg}$.

\section{Results and discussion}

\subsection{X-ray diffraction study}

The asymmetric unit of the title compound contains one m-xylylenediaminium cation, two perchlorate anions and one water molecule (Fig. 1). The atomic arrangement of the title compound can be described by three-dimensional network (Fig. 2a). While, organic cations, perchlorate anions and water molecules are linked together by $\mathrm{N}-\mathrm{H} \cdots \mathrm{O}, \mathrm{N}-\mathrm{H} \cdots \mathrm{OW}$, OW $-\mathrm{H} \ldots \mathrm{O}$ and $\mathrm{C}-\mathrm{H} \cdots \mathrm{O}$ type hydrogen bonds thus forming layers parallel to the plane (a,

b) centered at $\mathrm{z}=1 / 4$ and $3 / 4$.

The projection of a layer of this compound along the axis $\vec{c}$ (Fig. 2b) represents the organization of anions located in position $\mathrm{x}=0$ between which intercalate cations and water molecules in $\mathrm{x}=1 / 2$. Therefore, chlorine atoms, $\mathrm{Cl} 2$, are discrete and $\mathrm{Cl} 1 \mathrm{form}$ with water molecules corrugated channels $C_{2}^{2}(6)$ extending along the $a$-axis at $\mathrm{z}=1 / 4$ and $3 / 4$. These inorganic entities are allied to organic cations $\left(\mathrm{C}_{8} \mathrm{H}_{14} \mathrm{~N}_{2}\right)^{2+}$ through intricate hydrogen bonding.

The perchlorate anion displays its expected tetrahedral geometry around the chlorine atom. Interatomic bond lengths and angles of the perchlorate anion are respectively presented in the ranges $[1.4350(13)-1.4478(12) \AA]$ and $\left[108.48(7)-111.09(8)^{\circ}\right]$. Similar geometric features have also been observed in other crystal structures [19-20].

The calculated average values of the distortion indices corresponding to the different angles and distances in the $\mathrm{ClO}_{4}$ tetrahedra according to the method described by Baur [21] are: $\left[\mathrm{DI}(\mathrm{Cl1O})=0.0030, \quad \mathrm{DI}(\mathrm{OCl1O})=0.0054\right.$ and $\mathrm{DI}(\mathrm{OO})=0.0041$ for $\mathrm{Cl1O}_{4}$ and $\mathrm{DI}(\mathrm{Cl} 2 \mathrm{O})=0.0022, \mathrm{DI}(\mathrm{OCl} 2 \mathrm{O})=0.0048$ and $\mathrm{DI}(\mathrm{OO})=0.0026$ for $\left.\mathrm{Cl}_{2} \mathrm{O}_{4}\right]$. The comparison of the distortion indices shows a sturdy distortion of the $\mathrm{O}-\mathrm{Cl}-\mathrm{O}$ angles with respect to the $\mathrm{Cl}-\mathrm{O}$ 
distances from which the perchlorate anion has a tetrahedral geometry. It can be concluded that the $\mathrm{ClO}_{4}$ tetrahedron considers itself to be a regular arrangement of oxygen atoms with a chlorine atom slightly placed from the center of gravity $(\delta \mathrm{Cl} 1=0,008 \AA, \delta \mathrm{Cl} 2=0.000 \AA)$.

The Cl-O bond distances and $\mathrm{O}-\mathrm{Cl}-\mathrm{O}$ bond angle (Table 2) confirm a tetrahedral conformation, similar to other perchlorates quoted above.

The packing for the title compound established by hydrogen bonding (Table 3, Fig. 3) of types $\mathrm{N}-\mathrm{H} \ldots \mathrm{O}, \mathrm{N}-\mathrm{H} \ldots \mathrm{OW}, \mathrm{OW}-\mathrm{H} \ldots \mathrm{O}$ and $\mathrm{C}-\mathrm{H} \ldots \mathrm{O}$. The combination of $\mathrm{N}-\mathrm{H} . . \mathrm{O}(\mathrm{OW})$ and OW-H...O hydrogen bonds where N1, N2 and OW are donors generate rings $R_{4}^{3}(10), R_{3}^{3}$ (14) and $R_{3}^{2}(12)$ and another combination type N-H...O and C-H...O hydrogen bonds where $\mathrm{N} 2$ and $\mathrm{C} 5$ are donors forming a motif $R_{2}^{2}(9)$.

The geometrical characteristics of the organic part are reported in Table 2, N-C, C-C, distances and C-C-C and N-C-C angles are similar to others compound with same organic cation [22]. The aromatic ring of the cation is essentially planar with an r.m.s. deviation of $0.0014 \AA$.

Both ammonium goups cation adopt a cis conformation with respect to the benzene ring. The same conformation was observed in the compound m-xylylenediaminium dinitrate $\left(\mathrm{C}_{8} \mathrm{H}_{14} \mathrm{~N}_{2}\right)\left(\mathrm{NO}_{3}\right)_{2}$ [22]. The trans conformation has been observed in the sulfate $\mathrm{m}$ xylylenediammonium $\left(\mathrm{C}_{8} \mathrm{H}_{14} \mathrm{~N}_{2}\right)\left(\mathrm{SO}_{4}\right)$ structure [23]. Thus, the modification of cation conformation can be explained when the $\mathrm{SO}_{4}{ }^{2-}$ anion is changed by $\mathrm{ClO}_{4}$ -

The shortest distance between two parallel neighboring organic rings is 4,232 A, indicating a formation of cycle stacking [24].

\subsection{Hirshfeld analysis}

The intermolecular interactions were further evaluated by using the three-dimensional Hirshfeld surfaces [25] (Fig. 4) and two-dimensional fingerprint plots [26] (Fig. 5) generated by means of Crystal Explorer 3.1 [27]. The O...H/H...O contacts, which make the largest contribution to the Hirshfeld surfaces $(69.1 \%)$ and they are attributed to $\mathrm{N}-\mathrm{H} \ldots \mathrm{O}$ and $\mathrm{O}-$ H...O hydrogen-bonding interactions, appear as two sharp symmetric spikes in the twodimensional fingerprint maps with $\mathrm{d}_{\mathrm{e}}+\mathrm{d}_{\mathrm{i}}=1.8 \AA$ less than the sum of the van der Waals radius of the hydrogen $(1.09 \AA)$ and oxygen $(1.52 \AA)$ atoms. The H...H contacts with a percentage contribution of $17.5 \%$ appears in the middle of the scattered points in the twodimensional fingerprint maps at $\mathrm{d}_{\mathrm{e}}=\mathrm{d}_{\mathrm{i}}=1.2 \AA$ greater than of the van der Waals radius of the hydrogen atom $(1.09 \AA)$. 
The C...H/H...C has two symmetrical wings with a percent $7 \%$ and the O... (3.6 \%), C...O/O...C $(1.7 \%)$ and C...C $(0.8 \%)$ contacts also contribute to the Hirshfeld surface.

The enrechment ratio (ER) of a chemical element pair $(\mathrm{X}, \mathrm{Y})$ is defined as the ratio between the percentage of the actual contacts in the crystal and the theoretical percentage of the random contacts [28]. The enrichment ratio (ER) values are summarized in the Table 4.

The $\mathrm{O} \ldots \mathrm{H}$ contact appear with high enrichment $\mathrm{ER}_{\mathrm{OH}}=1.56$. So, this type of contacts are most frequent interactions due to the abundance of oxygen and hydrogen on the molecular surface $\left(\% \mathrm{~S}_{\mathrm{O}}=39.85 \%\right.$ and $\left.\% \mathrm{~S}_{\mathrm{H}}=55.55 \%\right)$. They are stabilizing interactions in crystal packing with the formation of hydrogen bonds N-H ... O and C-H ... O.

The $\mathrm{H} \ldots \mathrm{H}$ contacts account for $17.5 \%$ of the Hirshfeld surface, which is much lower by the calculated value for the random contacts $(30.85 \%)$ and these contacts adopt an enrichment ratio far from unity $\left(\mathrm{ER}_{\mathrm{HH}}=0.57\right)$ which can be explained by the fact that our compound has many oxygen acceptors $\left(\mathrm{ClO}_{4}\right)$, therefore hydrogen atoms interact with oxygen to form $\mathrm{O}$ $\mathrm{H} . . . \mathrm{O}, \mathrm{N}-\mathrm{H} . . . \mathrm{O}$ and $\mathrm{C}-\mathrm{H} . . . \mathrm{O}$ hydrogen bonds. As a result $\mathrm{H} . . \mathrm{H}$ interactions are impoverished due to this competition [28'].

The C...H/H...C hydrogen bonds represented $\mathrm{ER}_{\mathrm{CH}}=1.47$ and the C...C contacts between the cationic molecules, represent $\mathrm{ER}_{\mathrm{CC}}=4.3$. The high enrichment of C...C contact proves the presence of cycle stacking; this is confirmed by single crystal structure investigation. Whereas the $\mathrm{C} \ldots \mathrm{O}$ and $\mathrm{O} \ldots \mathrm{O}$ contacts are, respectively, slightly enriched and disfavored because of their small contributions to the Hirshfeld Surface $\left(\mathrm{ER}_{\mathrm{CO}}=0.5\right.$ and $\left.\mathrm{ER}_{\mathrm{OO}}=0.23\right)$.

\subsection{Calorimetry study}

The thermal behavior of $\left(\mathrm{C}_{8} \mathrm{H}_{14} \mathrm{~N}_{2}\right)\left(\mathrm{ClO}_{4}\right)_{2} \cdot \mathrm{H}_{2} \mathrm{O}$ was studied by DSC analysis under Argon atmosphere, with a heating between $298 \mathrm{~K}$ and $600 \mathrm{~K}$ at an average heating rate of $5 \mathrm{~K} / \mathrm{min}$. Furthermore, the DSC curve (Fig. 6) displays with increasing temperature a series of endothermic peaks centered at $336 \mathrm{~K}$ and $500 \mathrm{~K}$ and exothermic peak at $540 \mathrm{~K}$. In fact, the peak at $336 \mathrm{~K}$ corresponds to an elimination of the water molecule. After dehydration, this compound melts at around $500 \mathrm{~K}$ which is confirmed by a heating experiment with a Kofler Bench.

Finally, the latter peak at $545 \mathrm{~K}$ can be attributed to the decomposition of crystal (volatile gaseous materials and residual mass of carbon atoms).

\subsection{Spectroscopy studies}

FT-IR spectroscopy was used to verify the functional groups present in the crystal and to investigate their vibrational behavior in the solid state. The infrared spectrum (Fig. 7) was 
recorded in the 4000-400 $\mathrm{cm}^{-1}$ range and shows the bands corresponding to the characteristic vibrational modes of $\left(\mathrm{C}_{8} \mathrm{H}_{14} \mathrm{~N}_{2}\right)\left(\mathrm{ClO}_{4}\right)_{2} \cdot \mathrm{H}_{2} \mathrm{O}$ which compared with those of similar salts [2931].

In fact, the disubstituted aromatic ring containing an $\mathrm{N}-\mathrm{H}$ group absorption peak in the highfrequency region between $3621-2966 \mathrm{~cm}^{-1}$ are attributed to $\mathrm{N}-\mathrm{H}$ asymmetric and symmetric stretching vibration. Besides, the asymmetric and symmetric stretching vibrations of $\mathrm{NH}_{3}{ }^{+}$ group occur at 1626 and $1508 \mathrm{~cm}^{-1}$, respectively. The aromatic $\mathrm{C}-\mathrm{H}$ stretching vibration is observed at $2966 \mathrm{~cm}^{-1}$. The peak occurring at $2975 \mathrm{~cm}^{-1}$ is attributed to $\mathrm{CH}_{2}$ asymmetric stretching.

The $\mathrm{C}=\mathrm{C}$ stretching vibration appears at $1381 \mathrm{~cm}^{-1}$. The bands between 1135 and $1050 \mathrm{~cm}^{-1}$ are attributed to $\mathrm{C}-\mathrm{H}$ in-plane and out of plane bending vibration, $\mathrm{C}-\mathrm{N}$ stretching vibration and asymmetric and symmetric $\mathrm{C}-\mathrm{C}$ stretching modes.

For the inorganic part of title compound, a free $\mathrm{ClO}_{4}^{-}$ion with $\mathrm{T}_{\mathrm{d}}$ symmetry has four fundamental vibrations, the non-degenerate symmetric stretching mode $v_{\mathrm{s}}\left(\mathrm{A}_{1}\right)$, the doubly degenerate bending mode $\delta_{\mathrm{s}}(\mathrm{E})$, the triply asymmetric stretching mode $v_{\mathrm{as}}\left(\mathrm{F}_{2}\right)$, and the triply degenerate asymmetric bending mode $\delta_{\text {as }}\left(\mathrm{F}_{2}\right)$. The average frequencies observed for these modes are 928, 459, 1119, and $625 \mathrm{~cm}^{-1}$, respectively and the assignments of infrared and Raman bands have been performed according to the literature [32-34].

In fact, the intense peaks observed in spectrum IR at $1078 \mathrm{~cm}^{-1}$ assigned to the asymmetric stretching modes $v_{\text {as }}\left(\mathrm{ClO}_{4}^{-}\right)$. However, the band appearing near $618 \mathrm{~cm}^{-1}$ corresponds to the asymmetric bending mode $\delta_{\text {as }}\left(\mathrm{ClO}_{4}^{-}\right)$is observed at $618 \mathrm{~cm}^{-1}$.

The Raman spectra (Fig. 8) of perchlorate anion displayed bands at $932 \mathrm{~cm}^{-1}$ and $1116 \mathrm{~cm}^{-1}$ are attributed to the symmetric $v_{\mathrm{s}}$ and asymmetric $v_{\mathrm{as}}$ stretching mode of $\mathrm{ClO}_{4}^{-}$units, respectively. The weak bands at $502 \mathrm{~cm}^{-1}$ and $632 \mathrm{~cm}^{-1}$ can be assigned to the symmetric $\delta_{\mathrm{s}}$ and asymmetric $\delta_{\mathrm{as}}$ bending mode of $\mathrm{ClO}_{4}^{-}$respectively.

\subsection{Optical Absorption}

The electronic absorption spectra of $\left(\mathrm{C}_{8} \mathrm{H}_{14} \mathrm{~N}_{2}\right)\left(\mathrm{ClO}_{4}\right)_{2} \cdot \mathrm{H}_{2} \mathrm{O}$ in DMSO solution at room temperature and pure m-xylylenediamine (Fig. 9a) show a broad band at 280 and $278 \mathrm{~nm}$, respectively. This band is attributed to the $\pi-\pi^{*}$ transition of aromatic ring in $\mathrm{m}$ xylylenediaminium cation endorsed with the absorption band of pure amine.

The optical band gap was estimated by plotting (hv) versus $(\alpha h v)^{2}$ (Tauc's plot, Fig. 9b) [35]. From the graph, the optical band gap of the crystal was estimated to be $3.64 \mathrm{eV}$. This high band gap value indicates that the title compound may possess semiconducting properties and a 
high kinetic stability and low chemical reactivity [36], because it is energetically unfavorable to add electrons to a high-lying LUMO or to extract electrons from a low-lying HOMO [37]. The emission spectrum in the solid state at room temperature of the crystal is given in Fig. 10. The excitation of $\left(\mathrm{C}_{8} \mathrm{H}_{14} \mathrm{~N}_{2}\right)\left(\mathrm{ClO}_{4}\right)_{2} \cdot \mathrm{H}_{2} \mathrm{O}$ with $\lambda_{\mathrm{ex}}=276 \mathrm{~nm}$ shows that luminescence band observed at $\lambda_{\mathrm{em}}=317 \mathrm{~nm}$ can be attributed to $\pi^{*}-\pi$ transition of aromatic ring .

\section{Conclusions}

Single crystals of a novel perchlorate compound, $\left(\mathrm{C}_{8} \mathrm{H}_{14} \mathrm{~N}_{2}\right)\left(\mathrm{ClO}_{4}\right)_{2} \cdot \mathrm{H}_{2} \mathrm{O}$, have been developed at room temperature by slow evaporation solution growth technique. The atomic arrangement of the title compound can be described by three-dimensional network. Insight, organic cations, perchlorate anions and water molecules are linked together by $\mathrm{N}-\mathrm{H} \cdots \mathrm{O}, \mathrm{N}$ $-\mathrm{H} \cdots \mathrm{OW}, \mathrm{OW}-\mathrm{H} \ldots \mathrm{O}$ and $\mathrm{C}-\mathrm{H} \cdots \mathrm{O}$ type hydrogen bonds thus forming sheets parallel to the plane $(a, b)$ centered at $z=1 / 4$ and $3 / 4$. Hirshfeld surface investigation of the synthesis salt discloses the percentage of intermolecular contacts in the compound. The vibrational absorption bands were identified by Infrared and Raman spectroscopy. The optical properties were studied by optical absorption and luminescence. Indeed, the optical band gap of the crystal was estimated to be $3.64 \mathrm{eV}$. This high band gap value indicates that the $\mathrm{MXClO}_{4}$ may possess semiconducting properties and high kinetic stability.

\section{Acknowledgements}

This work was supported by the Ministry of Higher Education and Scientific Research of Tunisia.

\section{References}

[1'] R. Salmasi, A. Salimi, M. Gholizadeh, M. Rahmani, J. C. Garrison, Symmetric quaternary phosphonium cation and perchlorate/chlorate anions: Crystal structure, Database study and Hirshfeld surface analysis, J. Mol. Struct. 1179 (2019)

[1''] Y49-557. Shan, Z. Wang, X. Xu, B. Gao, Z. Ren, Bio-reduction of free and laden perchlorate by the pure and mixed perchlorate reducing bacteria: Considering the $\mathrm{pH}$ and coexisting nitrate, Chemosphere 205 (2018) 475-483.

[1] R. Lancaster, Fireworks: Principles and Practice, Chemical Publishing Co., Inc., New York, 1992. 
[2] J. Akhavan, The Chemistry of Explosives, seconded., RSC Paperbacks, Cambridge, 2004 .

[3] H. El Aribi, Y. J. Le Blanc, S. Antonsen, T. Sakuma, Analysis of perchlorate in foods and beverages by ion chromatography coupled with tandem mass spectrometry (ICESI- MS/MS), Anal Chim Acta 567(1) (2006) 39-47.

[4] H. P. Wagner, B. V. Pepich, C. Pohl, D. Later, K. Srinivasan, R. Lin, B. Deborba, D. J. Munch, Selective method for the analysis of perchlorate in drinking waters at nanograrn per liter levels, using two-dimensional ion chromatography with suppressed conductivity detection, J. Chromatogr. A (2007) 1155, 15-21.

[5] L. Chen, H. Chen, M. Shen, Z. Zhou, A. Ma, Analysis of perchlorate in milk powder and milk by hydrophilic interaction chromatography combined with tandem mass spectrometry, J. Agric. Food Chem. 58 (2010) 3736-3740.

[6] P. Winkler, M. Minteer, J. Willey, Analysis of perchlorate in water and soil by electrospray LC/MS/MS. Anal. Chem. 76 (2004) 469-473.

[7] L. Ye, H. You, J. Yao, X. Kang, L. Tang, Seasonal variation and factors influencing perchlorate in water, snow, soil and corns in Northeastern China, Chemosphere 90 (2013) 2493-2498.

[8] Y. Shi, P. Zhang, Y. Wang, J. Shi, Y. Cai, S. Mou, G. Jiang, Perchlorate in sewage sludge, rice, bottled water and milk collected from different areas in China, Environ. Int. 33 (2007) 955-962.

[9] A. Srinivasan, T. Viraraghavan, Perchlorate: Health Effects and Technologies for Its Removal from Water Resources, Int. J. Environ. Res. Public Health 6 (2009) 14181442 .

[10] R. Srinivasan, G. Sorial, Treatment of perchlorate in drinking water: A critical review, Sep. Purif. Technol. 69 (2009) 7-21.

[11] E. T. Urbansky, Perchlorate Chemistry: Implications for Analysis and Remediation, Biorem. J. 2 (1998) 81-95

[12] K. Kaabi, M. El Glaoui, E. Jeanneau, M. Rzaigui, C. Ben Nasr, 1-Benzylpiperazine1,4-diium bis(perchlorate) monohydrate, Acta Cryst. E66 (2010) o1722.

[13] C. Ben Mleh, T. Roisnel, H. Marouani, Synthesis and Crystal Structure of a New 2,6-dimethyl piperazine-1,4-diium Perchlorate Monohydrate: $\left(\mathrm{C}_{6} \mathrm{H}_{16} \mathrm{~N}_{2}\right)\left(\mathrm{ClO}_{4}\right)_{2} \cdot \mathrm{H}_{2} \mathrm{O}$, Crystallogr. Rep+, 62 (2017) 246-248. 
[14] C. Ben Mleh, T. Roisnel, H. Marouani, trans-2,5-Dimethylpiperazine-1,4-diium bis(perchlorate) dihydrate: crystal structure and Hirshfeld surface analysis, Acta Cryst. E72 (2015) 593-596.

[15] Bruker, APEX2, SAINT and SADABS, Bruker AXS Inc., Madison, Wisconsin, USA, 2006.

[16] A. Altomare, M. C. Burla, M. Camalli, G. L. Cascarano, C. Giacovazzo, A. Guagliardi, A. G. G. Moliterni, G. Polidori, R. Spagna, J. Appl. Cryst. 32 (1999) 115119.

[17] G.M. Sheldrick, Crystal structure refinement with SHELXL, Acta Cryst. C71 (2015) 3-8.

[18] L. J. Farrugia, WinGX and ORTEP for windows: an update, J. Appl. Cryst. 45 (2012) 849-854.

[19] D. Podsiadła, O. Czupinski, M. Rospenk, Z. Czapla,. J. Mol. Struct. 1126 (2016) $63-73$.

[20] G. B. Parravicini, F. Marabelli, F. Floris, V. Pasquali, J. Parravicini, P. Ferloni, Mater. Chem. Phys. 147 (2014) 120-126.

[21] W. H. Baur, Acta Cryst. B30 (1974) 1191-1195.

[22] S. Gatfaoui, H. Dhaouadi, T. Roisnel, M. Rzaigui, H. Marouani, Acta Cryst. E70 (2014) 398-399.

[23] A. Guesmi, S. Gatfaoui, T. Roisnel, H. Marouani, Acta Cryst. E72 (2016) 593-596.

[24] J. Janiak, J. Chem. Soc. Dalton Trans (2000) 3885-3896.

[25] M. A. Spackman, D. Jayatilaka, Cryst Eng Comm; 11 (2009) 19-32.

[26] M. A. Spackman, J. J. McKinnon, Cryst Eng Comm 4 (2002) 378- 392.

[27] S. K. Wolff, D. J. Grimwood, J. J. McKinnon, M. J. Turner, D. Jayatilaka, M. A. Spackman, CrystalExplorer 3.1, University of Western Australia, Crawley, Western Australia, 2013, 2005e2013, http://hirshfeldsurface.net/CrystalExplorer.

[28] C. Jelsch, K. Ejsmont, L. Huder, The enrichment ratio of atomic contacts in crystals, an indicator derived from the Hirshfeld surface analysis, IUCrJ 1 (2014) 119-128.

[28'] C. Jelsch, Y. Bibila, M. Bisseyou, Atom interaction propensities of oxygenated chemical functions in crystal packings, IUCrJ 4 (2017) 158-174.

[29] S. Seif, M. Cakmak, Stress - Optical behavior of Poly $(m$-xylylenediamine adipamide) (Nylon MXD6): Influence of molecular weight, Polymer 51 (2010) 37623773. 
[30] H. Li, S.W. Lim, J. H. Kim, G. Seo, Activity improvement of xylylenediamine as a base catalyst by incorporation in SBA-15 mesoporous material, J. Mol. Catal. A: Chem. 380 (2013) 144- 151.

[31] D. Podsiadła, O. Czupinski, M. Rospenk, Z. Czapla, Vibrational spectroscopic, optical and thermal properties of a hybride pyridazine perchlorate complex-An experimental and theoretical study, J. Mol. Struct. 1126 (2016) 63-73.

[32] V. Murugesan, M. Saravanabhavan, M. Sekar., Synthesis, Spectral, Structural Characterization and Biological Investigation of Organic Charge Transfer Complex: m-xylylenediammoinium-bis (p-toluenesulfonate) monohydrate, J. Photochem. Photobiol. B 148 (2015) 358-365.

[33] G. B. Parravicini, F. Marabelli, F. Floris, V. Pasquali, J. Parravicini, P. Ferloni, Thermal evolution of tetramethylammonium tetrafluoborate and perchlorate investigated through dielectric and IR spectroscopy, Mater. Chem. Phys. 147 (2014) $120-126$.

[34] G. Hertzberg, Infrared and Raman Spectra of Polyatomic Molecules. Van Nostrand, New York, 1966.

[35] J. Tauc, Optical properties and electronic structure of amorphous Ge and Si, Mater. Res. Bull. 3 (1968) 37-46.

[36] H. E. Ahmed, S. Kamoun, Crystal structure, vibrational spectra, optical and DFT studies of bis (3-azaniumylpropyl) azanium pentachloroantimonate (III) chloride monohydrate $\left(\mathrm{C}_{6} \mathrm{H}_{20} \mathrm{~N}_{3}\right) \mathrm{SbCl}_{5} \cdot \mathrm{Cl} \cdot \mathrm{H}_{2} \mathrm{O}$, Spectrochim. Acta, Part A 184 (2017) 38-46.

[37] J. Aihara, Reduced HOMO-LUMO Gap as an Index of Kinetic Stability for Polycyclic Aromatic Hydrocarbons, J. Phys. Chem. A 103 (1999) 7487-7495. 


\section{Figure captions}

Fig. 1. An ORTEP view of $\left(\mathrm{C}_{8} \mathrm{H}_{14} \mathrm{~N}_{2}\right)\left(\mathrm{ClO}_{4}\right)_{2} \cdot \mathrm{H}_{2} \mathrm{O}$ with the atom-labeling scheme. Displacement ellipsoids are drawn at the $30 \%$ probability level.

Fig. 2. (a) Projection of $\left(\mathrm{C}_{8} \mathrm{H}_{14} \mathrm{~N}_{2}\right)\left(\mathrm{ClO}_{4}\right)_{2} \cdot \mathrm{H}_{2} \mathrm{O}$ along the a axis. (Cg: gravity center of the ring $\mathrm{C} 2-\mathrm{C} 3-\mathrm{C} 4-\mathrm{C} 5-\mathrm{C} 6-\mathrm{C} 7)$. (b) Projection of a sheet of the sample along the c axis.

Fig. 3. Hydrogen bond graphs in $\left(\mathrm{C}_{8} \mathrm{H}_{14} \mathrm{~N}_{2}\right)\left(\mathrm{ClO}_{4}\right)_{2} \cdot \mathrm{H}_{2} \mathrm{O}$.

Fig. 4. Hirshfeld surface around the constituents of (I) colored according to $d_{\text {norm. }}$. The surfaces are shown as transparent to allow visualization of the orientation and conformation of the functional groups.

Fig. 5. 2D Fingerprint plots of the contacts in the crystal (I).

Fig. 6. DSC curve of grown of $\left(\mathrm{C}_{8} \mathrm{H}_{14} \mathrm{~N}_{2}\right)\left(\mathrm{ClO}_{4}\right)_{2} \cdot \mathrm{H}_{2} \mathrm{O}$.

Fig. 7. Infrared spectrum of $\left(\mathrm{C}_{8} \mathrm{H}_{14} \mathrm{~N}_{2}\right)\left(\mathrm{ClO}_{4}\right)_{2} \cdot \mathrm{H}_{2} \mathrm{O}$.

Fig. 8. Raman spectrum of $\left(\mathrm{C}_{8} \mathrm{H}_{14} \mathrm{~N}_{2}\right)\left(\mathrm{ClO}_{4}\right)_{2} \cdot \mathrm{H}_{2} \mathrm{O}$.

Fig. 9. (a) $\mathrm{UV}-\mathrm{Vis}$ spectrum of $\left(\mathrm{C}_{8} \mathrm{H}_{14} \mathrm{~N}_{2}\right)\left(\mathrm{ClO}_{4}\right)_{2} \cdot \mathrm{H}_{2} \mathrm{O}\left(\mathrm{MXClO}_{4}\right)$ and pure amine (MX).

(b) Optical band gap spectrum of $\left(\mathrm{C}_{8} \mathrm{H}_{14} \mathrm{~N}_{2}\right)\left(\mathrm{ClO}_{4}\right)_{2} \cdot \mathrm{H}_{2} \mathrm{O}$ obtained via Tauc model.

Fig. 10. View of emission spectra for $\left(\mathrm{C}_{8} \mathrm{H}_{14} \mathrm{~N}_{2}\right)\left(\mathrm{ClO}_{4}\right)_{2} \cdot \mathrm{H}_{2} \mathrm{O}$. 


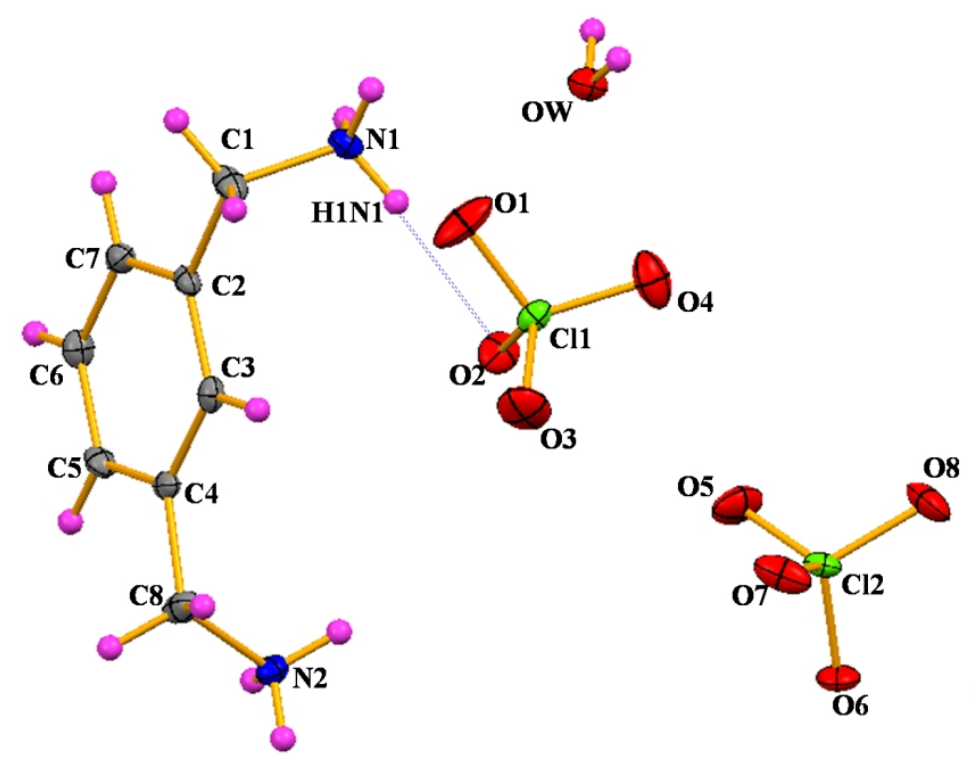

Fig. 1 


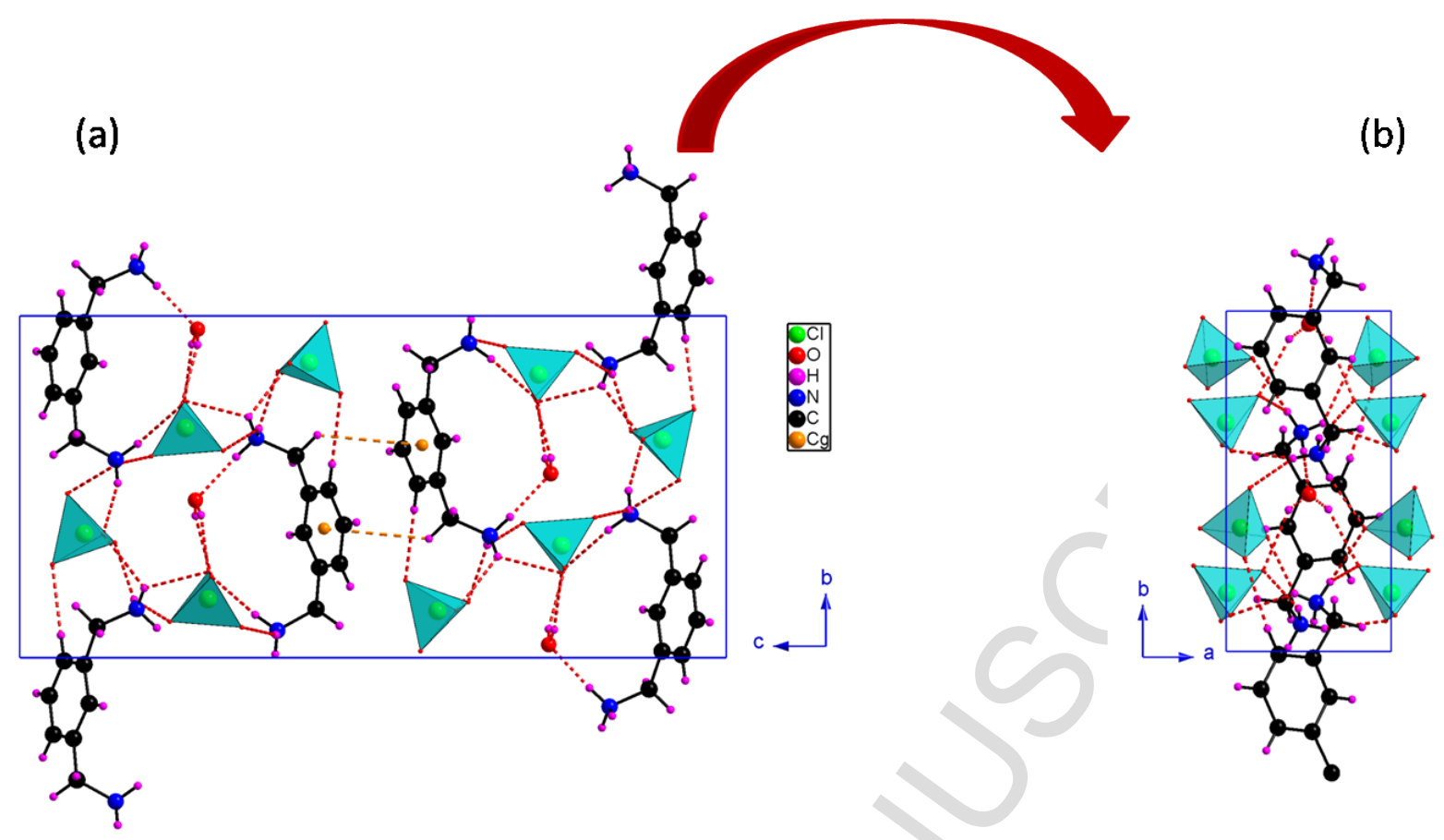

Fig. 2 

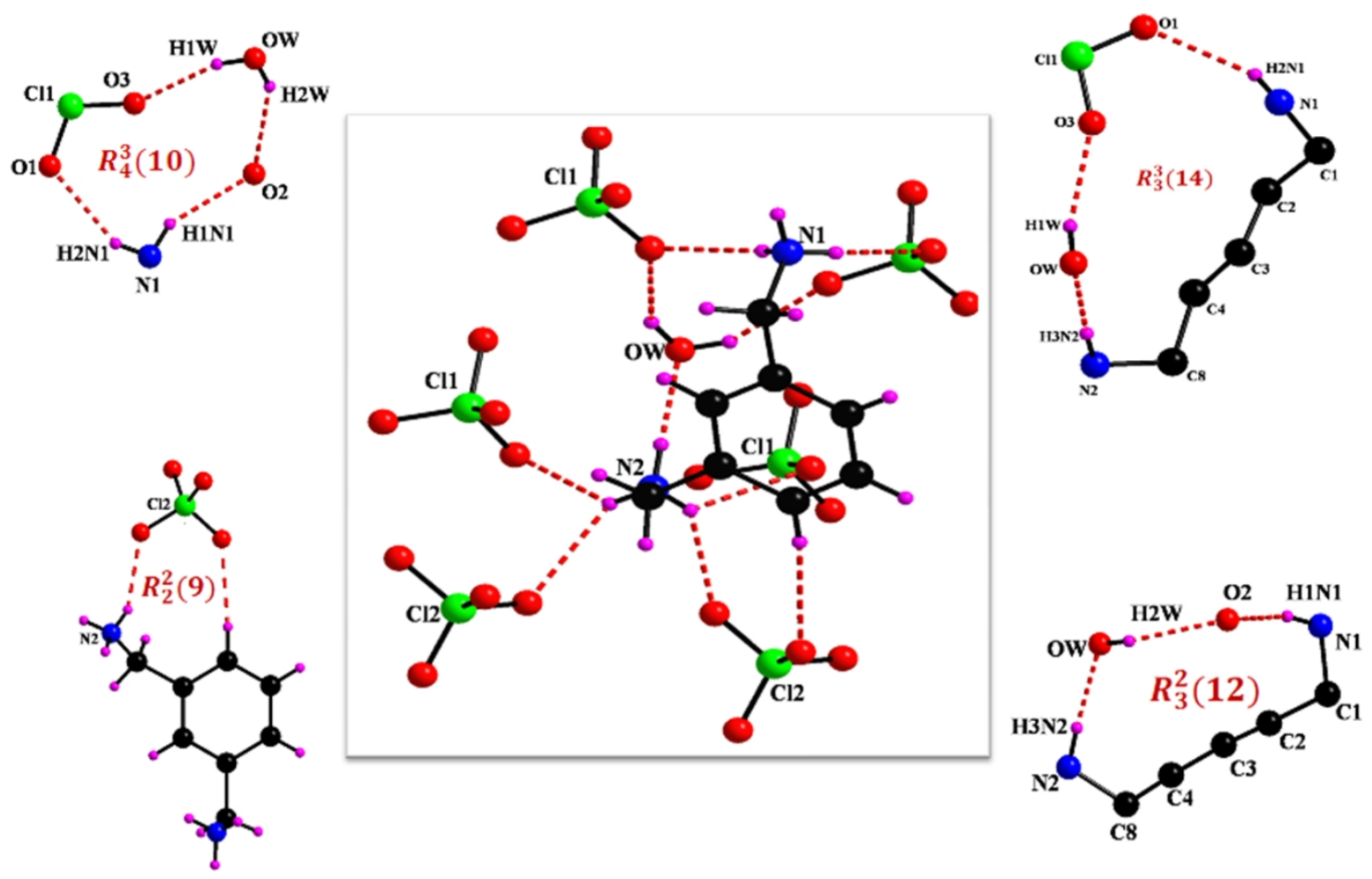

Fig. 3 


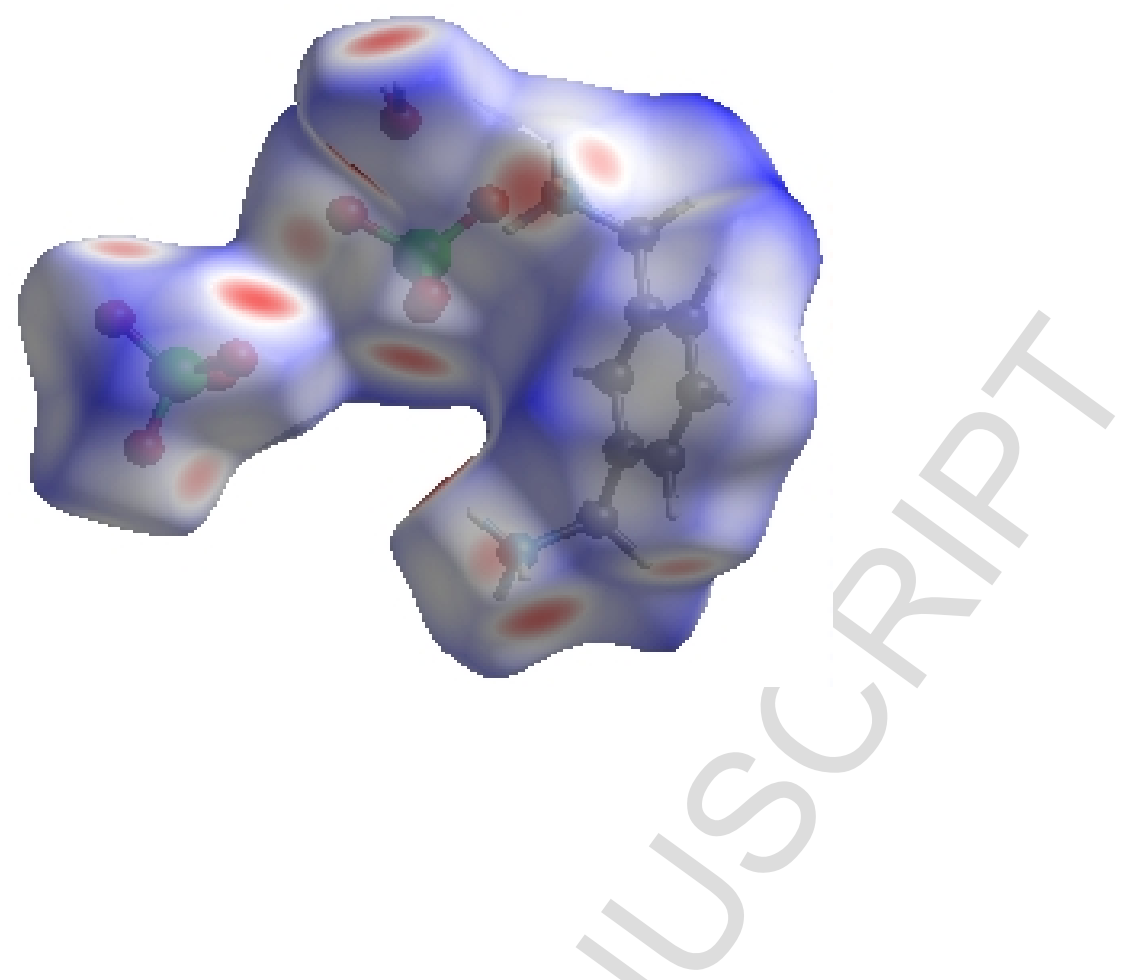

Fig. 4 

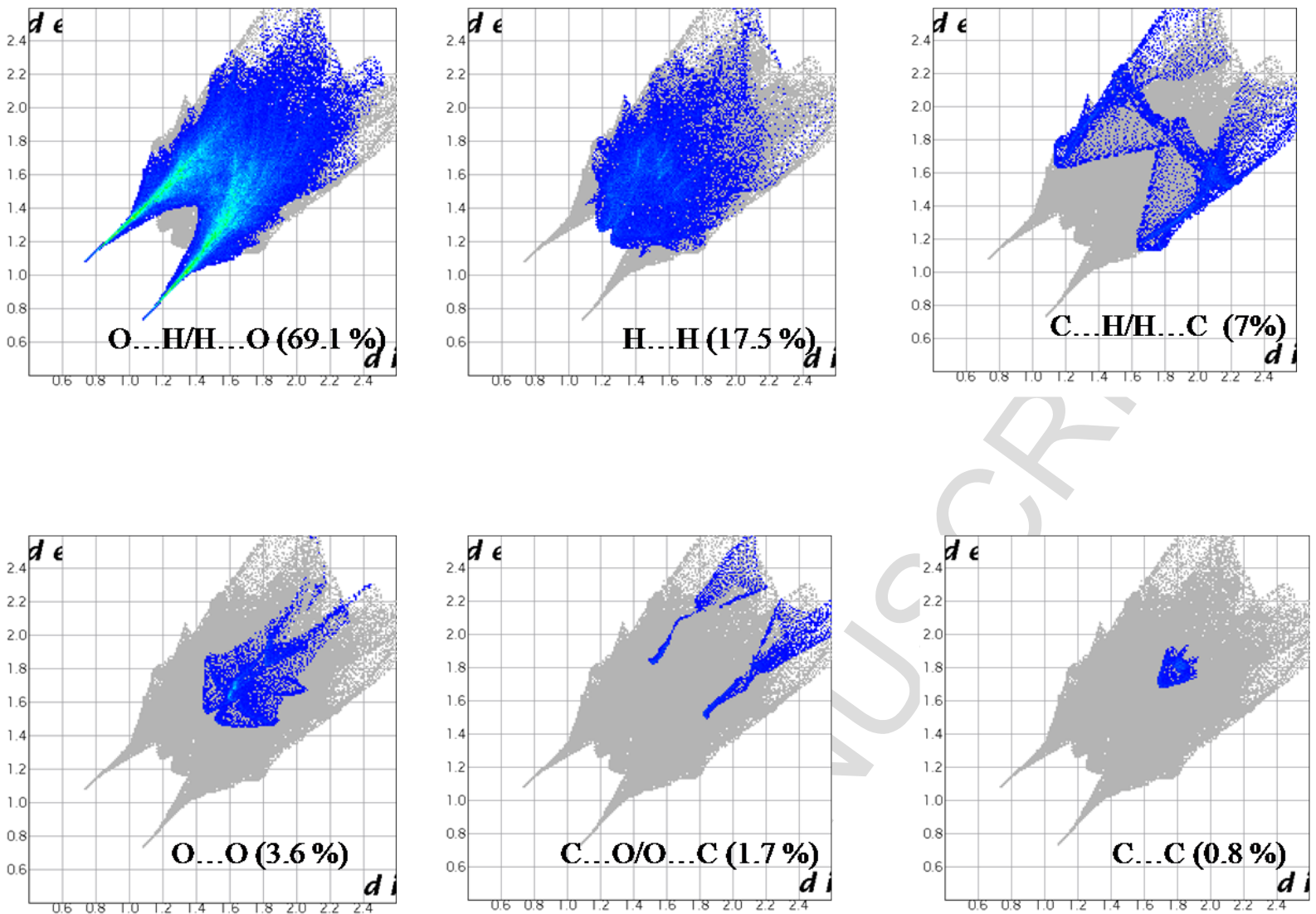

Fig. 5 


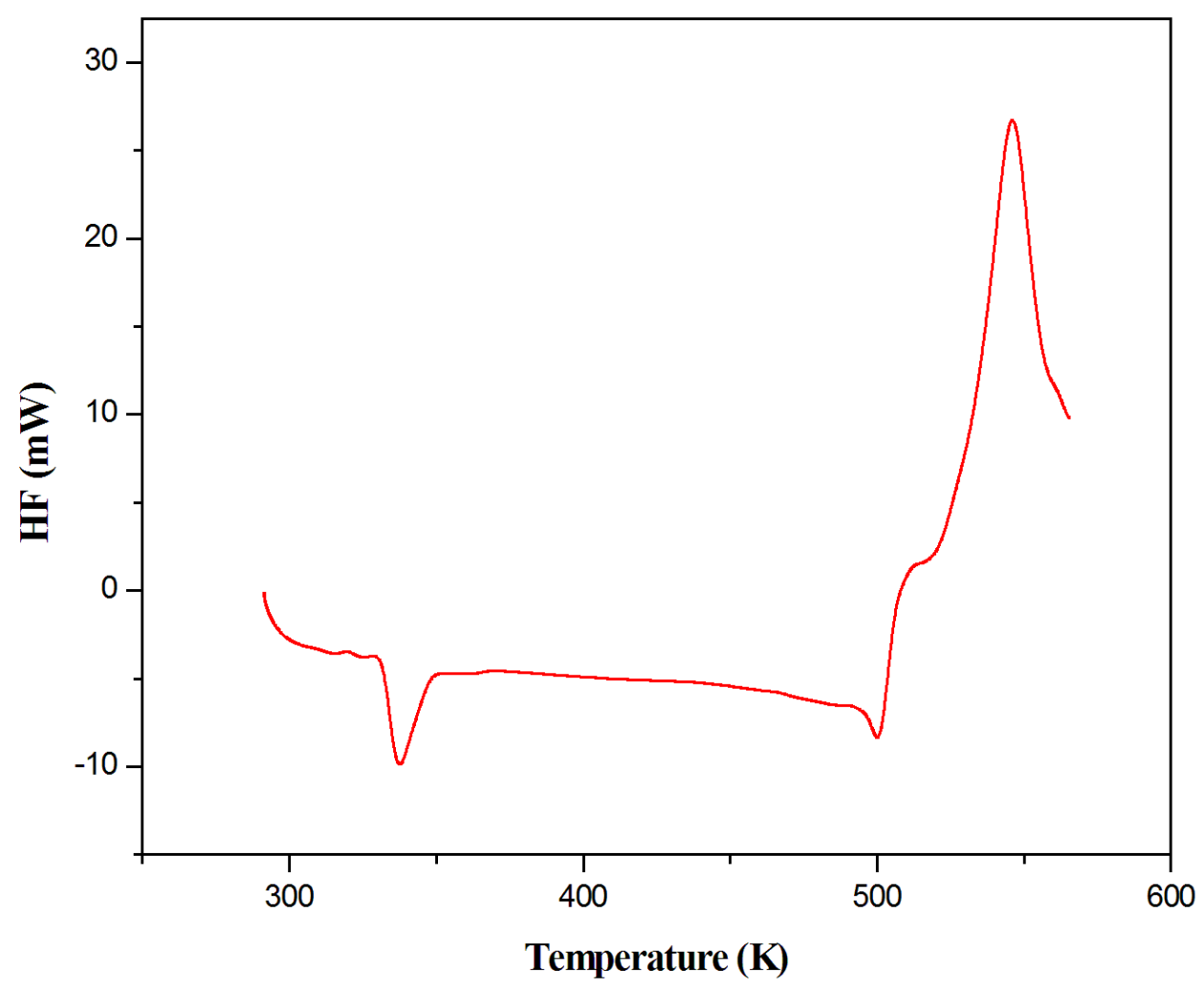

Fig. 6 


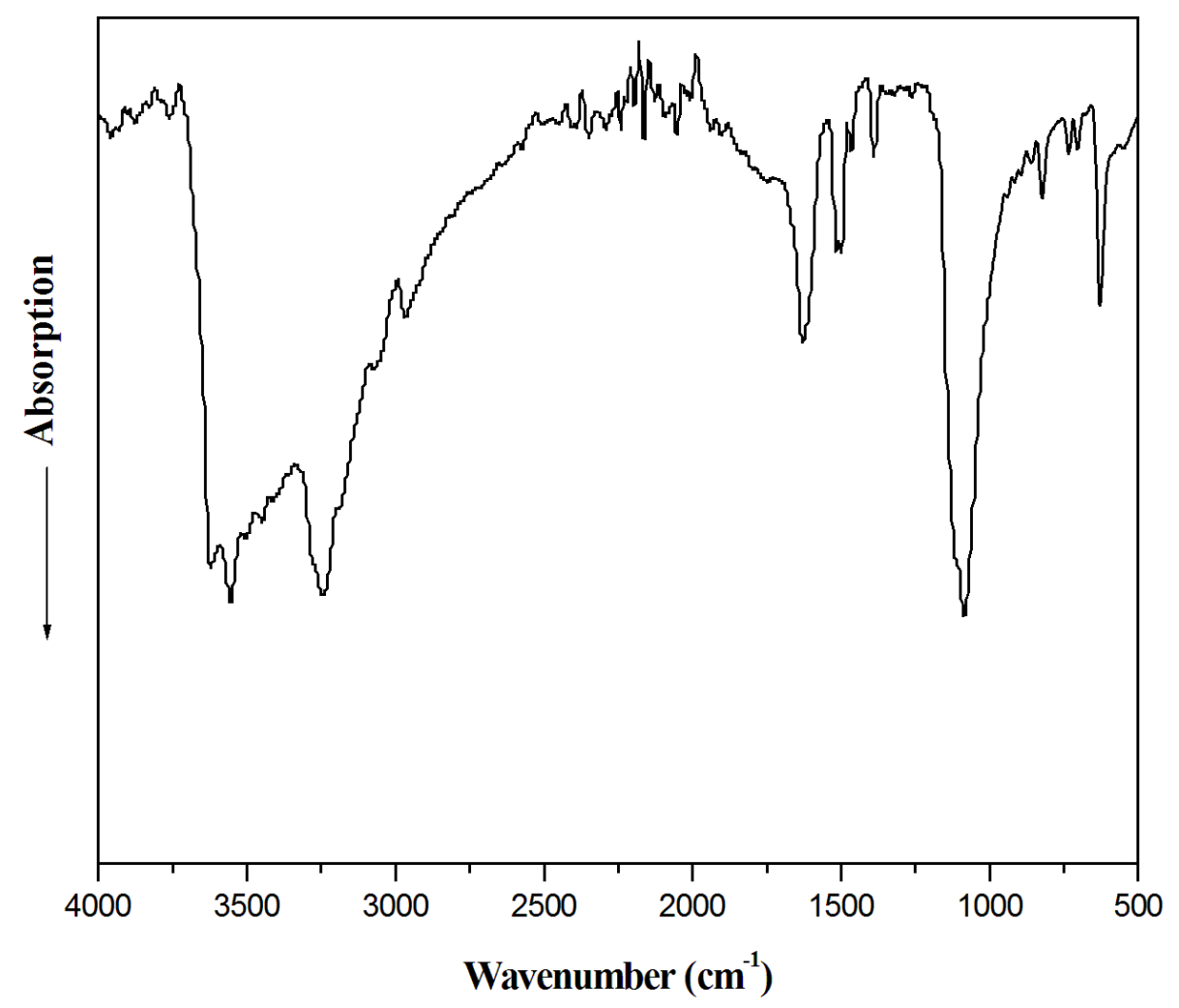

Fig. 7 


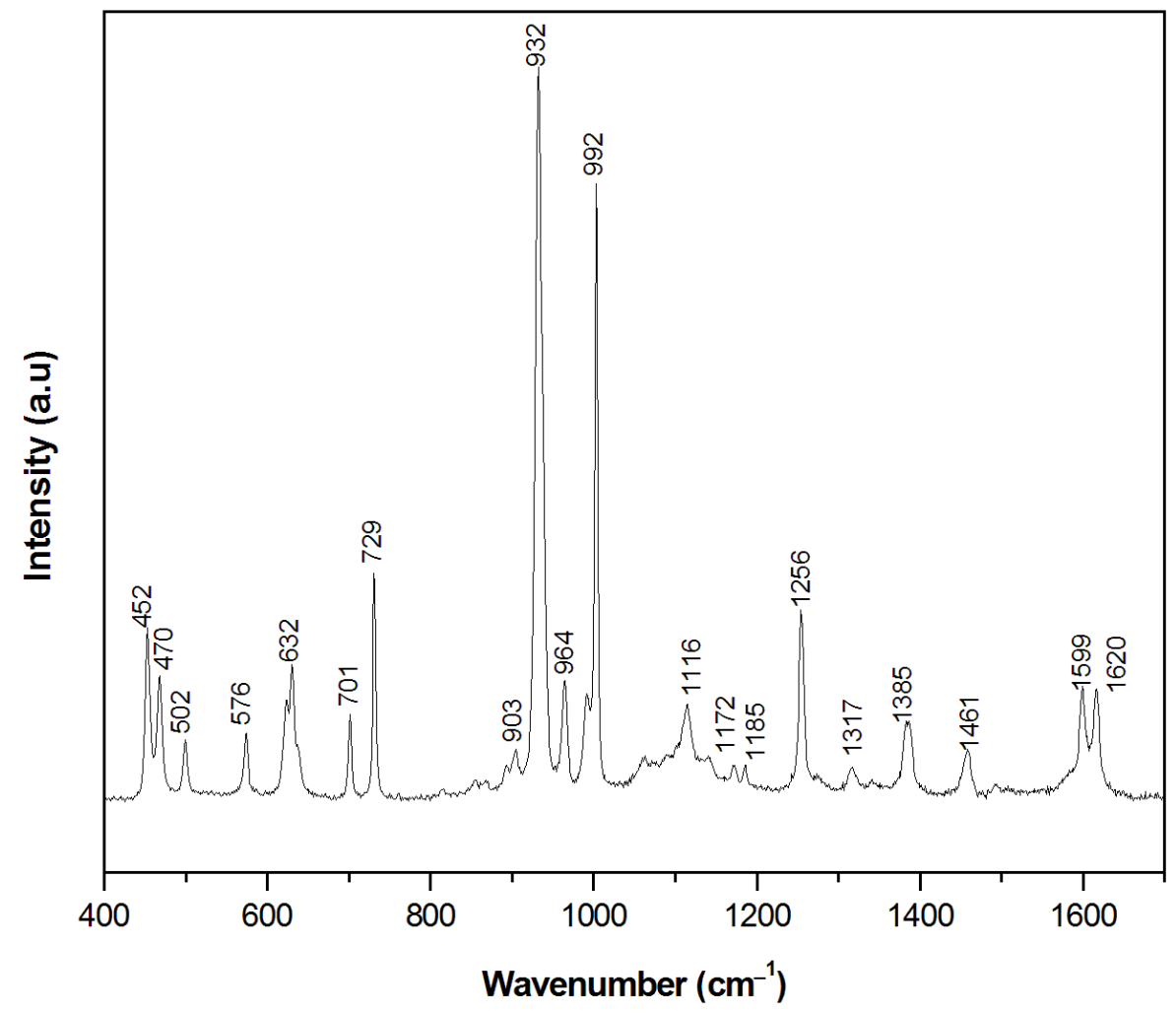

Fig. 8 

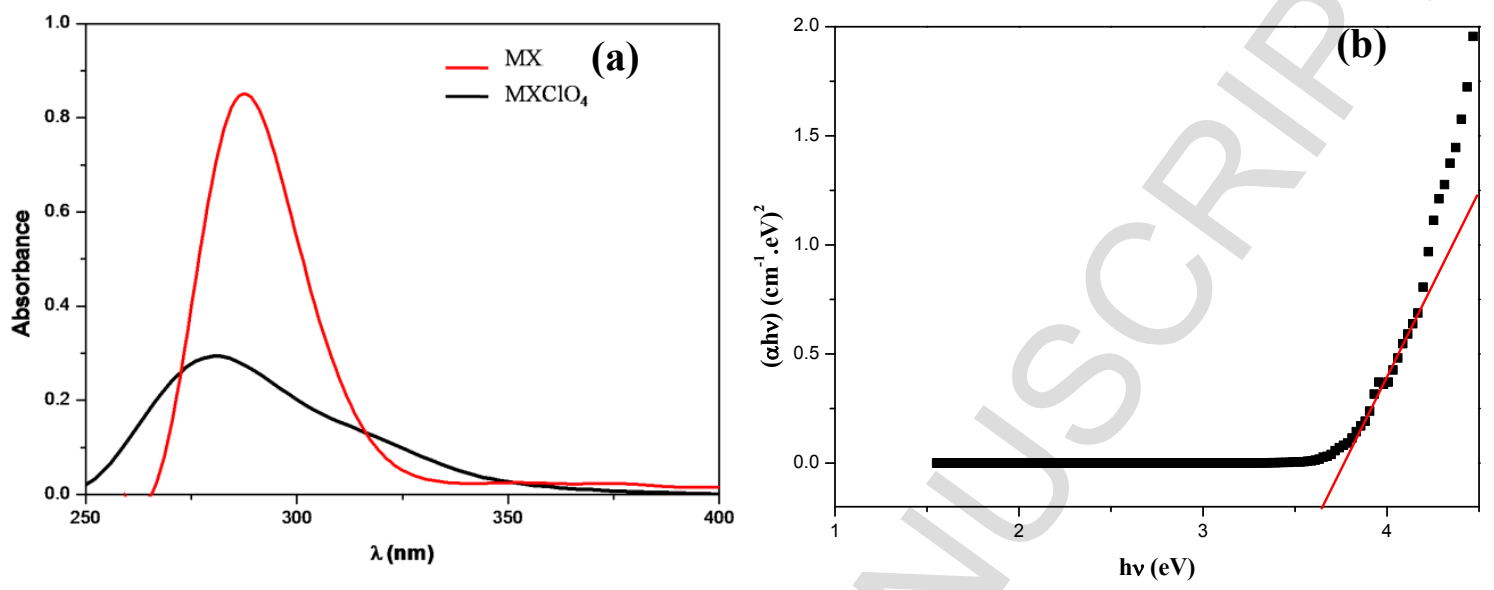

Fig. 9 


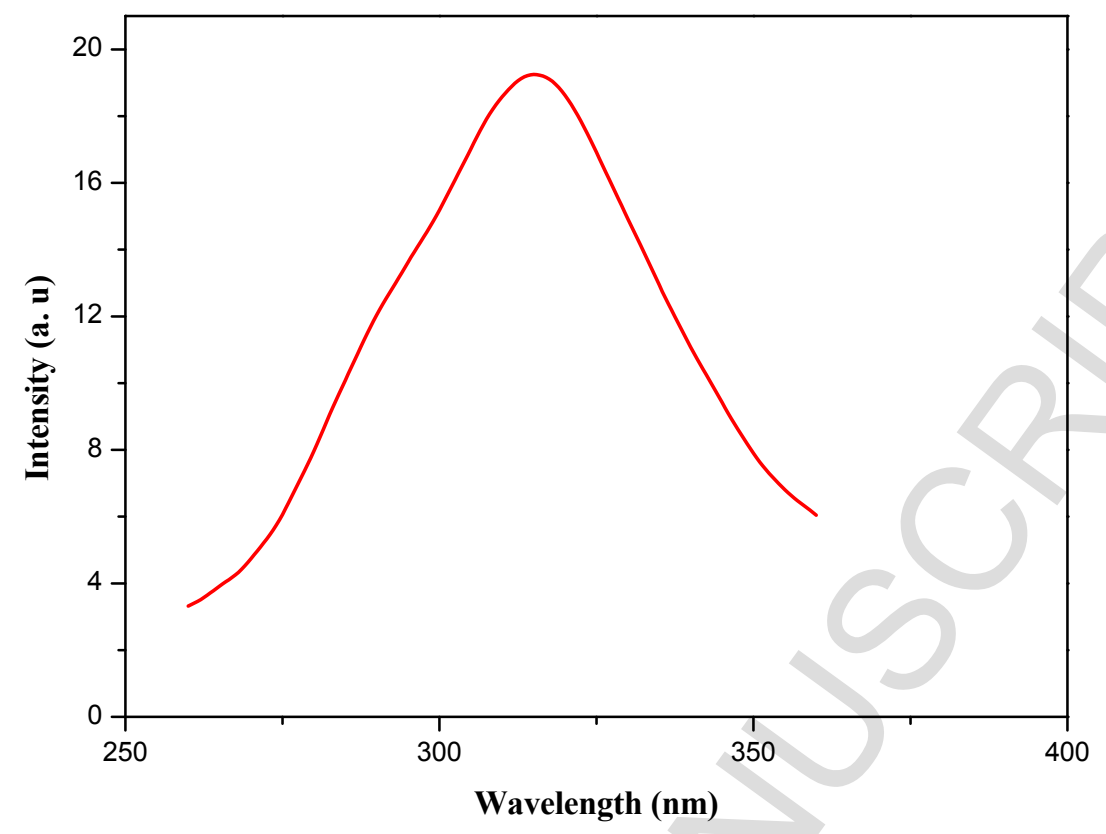

Fig. 10 
- A new organic-inorganic compound, $\mathrm{MXClO}_{4}$, was prepared at room temperature.

- The atomic arrangement of the synthesized compound shows three-dimensional network.

- $\mathrm{MXClO}_{4}$ was characterized by X ray, FT-IR, Raman and UV spectroscopy.

- The intermolecular interactions were analyzed by Hirshfeld surfaces. 